\title{
Health Effect on and Adaptation of the Elderly Affected by Floods
}

\author{
Somjinda CHOMPUNUD and Wanpen INKAEW
}

The Thai Red Cross College of Nursing, Community Health and Psychiatric Nursing, Bangkok, Thailand

\begin{abstract}
Aim: The aim of the study was to investigate the health effect on and adaptation of the elderly affected by floods in the Lat Krabang District, Bangkok, Thailand in 2011.

Methods: A cross-sectional descriptive study was conducted. Data were collected from 290 elderly participants who were affected by the floods using questionnaires.

Results: The elderly participants had previous experience with flooding, but the massive flooding in 2011 was the most severe compared to any other experiences in the past. Physical health effects included muscle pain (35.2\%), athlete's foot (28.3\%), and skin rash $(23.1 \%)$. The psychological health effects $(24.3 \%)$ encountered included insomnia, constant stress and tension, attention deficit, and discontentment. Most elderly (89.3\%) decided not to relocate thinking they could still live at home, but they were concerned about the safety of their property. In regards to preparation for the flood, they prepared consumer goods, medication, and emergency kits. In addition, they kept abreast with news on television and public announcements in the community. They also helped clear the drainage system and prepared contact information of children, relatives, and government offices in case they needed assistance. Finally, to reduce possible damage to the property, they moved their belongings to high places, built sandbag walls, raised the house level, and prepared a water pump.

Conclusion: The 2011 Thailand floods had adverse effects on physical and psychological health of the elderly people. To ensure better management for this vulnerable group, plans to respond to possible disasters need to be devised by relevant agencies to reduce flood-related health impacts.
\end{abstract}

Key words: adaptation, elderly, flood, health effect

\section{INTRODUCTION}

Floods are of significant public concern in Thailand during the months of May-September every year. Thailand has been facing heavy flood inundation in every region. During 17 years between the years 2000 and 2016, more than 2,000 victims were killed and nearly 37 million people were affected by flood disasters (CRED, 2017). The year 2011 was a very notable year in Thailand, as the country endured enormous damage in

Correspondence: Somjinda Chompunud, The Thai Red Cross College of Nursing, Community Health and Psychiatric Nursing, 1873 Rama IV Road, Patumwan, Bangkok 10330, Thailand. Email: csomjinda@gmail.com

Received 24 May 2016; accepted 5 December 2017; J-STAGE advance published 4 October 2018. the wake of the worst flooding in at least five decades. More than 800 people were killed, and millions of residents were either left homeless or displaced following significant flooding. Economic losses were estimated by the World Bank at US\$45.7 billion, making the floods one of the top five costliest natural disasters in modern history (National Disaster Prevention and Mitigation Committee, Thailand, 2015). In total, 65 of Thailand's 77 provinces were affected during this timeframe, and damage was widespread and severe in many locations. In one of the affected provinces, Bangkok Metropolitan Administration, $84.3 \%$ of the households were flooded, which was higher than any other region nationwide. The Lat Krabang District, on the eastern side of Bangkok, had been seriously affected by the flooding. A total of 42 out of 62 communities were affected by this flood (National Statistics Office, 2012). The aforementioned situation not 
only caused economic problems, but it also resulted in both short-term and long-term damages that had a great impact on the health of the Thai citizens, including the occurrence of different types of diseases brought about by flood waters, poisonous animals, excessive waste, a shortage of medication, injuries or deaths caused by electrocution, accidents, and mental health problems.

Elderly people are particularly vulnerable when a disaster strikes (World Health Organization, 2017). They may also suffer from mobility, cognitive, sensory, social, and economic limitations that can impede their ability to function and to adapt in disasters (Allen, 2010).

The consequences of aging limit elderly individuals' ability to respond to disaster warnings and take protective action, leading to higher mortality and injury rates. Advancing age correlates with a decline in physical and mental health functions, as well as a greater likelihood of having chronic health concerns or special needs that increase physical frailty and vulnerability. In terms of adaptation, their age could adversely influence their actions to prevent the extension of flooding or to reduce the negative impacts of flooding. Changes in routines, travel, and unfamiliar environments (such as a postdisaster relocation or shelter) can cause agitation, wandering, insomnia, and stress in elderly people as well (Chae, Kim, Rhee, \& Henderson, 2005; Pinyaphong, 2008; Sidet \& Inmuong, 2010). However, there have been few studies of the health effects and adaptation of elderly persons, particularly the vulnerable groups residing in Lat Krabang District, in an area with annual flood problems. Therefore, the current study aimed to assess elderly health effects caused by flooding, as well as explore their adaptation to minimize the effects of flooding.

\section{METHODS}

The study area was Lat Krabang District, Bangkok, Thailand, consisting of six sub-districts, two of which were randomly selected with four communities, which were also randomly selected (two communities per subdistrict). Lat Krabang District is located in the eastern side of Bangkok, Thailand (Figure 1). It stands outside the levees and floodwalls to receive water flowing down from the North. Most of the households in Lat Krabang District are found to have been affected by flooding every year.

A descriptive cross-sectional design was used in this study. The sample size was estimated by using a formula to estimate ratios (Fowler, Jarvis, \& Chevannes, 2002).

$$
\mathrm{n}=\frac{1.96^{2} \mathrm{p}(1-\mathrm{q})}{\mathrm{e}^{2}}
$$

In 2010 , the population in Thailand was $63,878,267$ people; $13,485,963$ (21\%) of whom suffered as a result of flooding. The population of this study comprised 13,640 elderly people living in communities in Lat Krabang District, Bangkok, Thailand who met the inclusion criteria (Department of Provincial Administration, 2010). Based on these criteria, at least 244 participants were recruited to meet the required sample size. The sample group was selected by cluster sampling. In total, the number of participants was 290 elderly people who had lived in the communities and experienced the flood disaster in 2011.

Three instruments were used in this study. The first instrument, the demographic characteristics questionnaire elicited data regarding demographic characteristics, physical health condition, and self-reported health effects. The health effects asked about were flood-related disease,

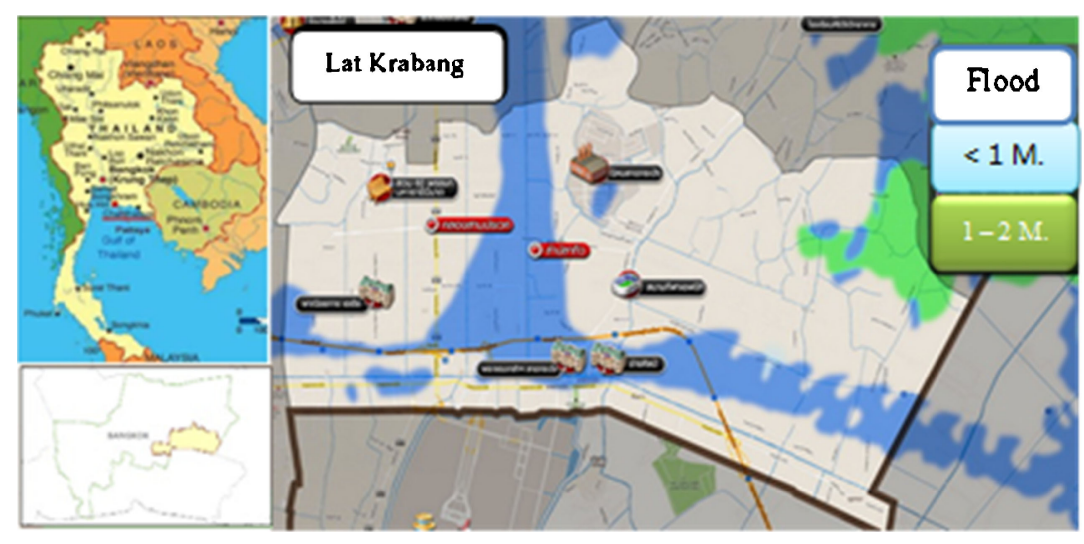

Figure 1 Location map of the study area. 
Table 1 A questionnaire sample of health effects reported by elderly study participants

\begin{tabular}{|c|c|c|}
\hline Health impacts items & Yes & No \\
\hline 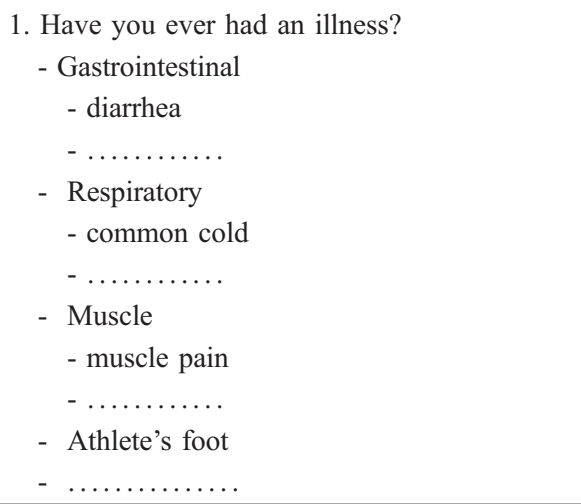 & & \\
\hline $\begin{array}{l}\text { 2. Have you ever had an accident? } \\
\text { - Electric shock } \\
-\ldots \ldots \ldots \ldots \text {. }\end{array}$ & & \\
\hline $\begin{array}{l}\text { 3. Have you ever had animal bites? } \\
\text { - Snakes } \\
-\quad \ldots \ldots \ldots \ldots \ldots\end{array}$ & & \\
\hline $\begin{array}{l}\text { 4. Have you ever had any treatment problems? } \\
\text { - No prescription given by the doctor } \\
\text { - Inconvenience traveling to a healthcare } \\
\text { service center } \\
\text { - Inability to keep the doctor's appointment } \\
\text { - . . ............. }\end{array}$ & & \\
\hline
\end{tabular}

accidents, animal bites and medical treatment (Table 1). The second instrument, the General Health Questionnaire (GHQ-12) Thai version was a 12-item self-administered questionnaire developed by the Thailand Department of Mental Health (2011). The GHQ-12 used a bi-modal score $(0,1)$, with the scores ranging from 0 to 12 . The GHQ-12 cut-off score of five points or higher indicated mental health problems. The third instrument was the experience of flood and adaptation (preparation for the next flood) questionnaire, which elicited data regarding the elderly's experience with the flood and adaptation (preparation for the next flood) (Table 2).

Analyses were conducted using IBM SPSS Statistics Version 22.0 (IBM Corporation., 2013). The data were analyzed by means of descriptive statistics including frequency, percentage, and mean values.

\section{Ethical considerations}

Protection of human subject approval was obtained from the Institutional Review Board on Research Involving
Table 2 A questionnaire sample of adaptation tasks for future floods reported by elderly study participants

1. Preparation of consumer goods and important documents $\square$ Storing consumer goods such as drinking water, rice, etc.

$\square$ Keeping documents and valuables in a plastic bag $\square$ Preparing medication

$\square$ Preparing emergency kits that include matches, candles, etc. a..............

2. Keeping up with the news and planning for evacuation

$\square$ Following flood forecasts on television

$\square$ Paying attention to community public announcements

Contacting children, relatives, or friends when in need

a.............

3. Modification of residence to reduce severity of flood-related damage

$\square$ Putting belonging up high to avoid damage

$\square$ Building sandbag walls

$\square$ Preparing space to move belongings to

$\square \ldots \ldots \ldots \ldots \ldots \ldots$

Others

Human Subjects of the Thai Red Cross College of Nursing. All participants were informed of the study's objectives, anonymity, confidentiality procedures, and their right to refuse to continue, at any time, without repercussions. The participants provided both verbal and written consent to participate in the study.

\section{RESULTS}

The mean age of the elderly participants was 68.9 years. More than half, or $57.2 \%$, were aged $60-69$ years, $32.5 \%$ were aged $70-79$ years, and $10.3 \%$ were aged 80 years and older. Almost two-thirds of the participants, or $64.1 \%$, were female, and $61.4 \%$ were married. Most of them, or $82.4 \%$, completed primary education, and more than two-thirds, or $69.3 \%$, were unemployed. Their mean income was less than US $\$ 143$ ( $<5,000$ baht) per month $(68.6 \%)$, and most had sufficient income with no savings $(71.0 \%)$. Moreover, slightly over half of the participants $(51.8 \%)$ had two to four family members. In terms of health, approximately three-quarters $(74.5 \%)$ had chronic diseases, with the largest group having hypertension (46.9\%), followed by diabetes mellitus $(30.0 \%)$ and high blood cholesterol (13.8\%) (Table 3).

With regard to health effects experienced during and after the flooding, the elderly participants had the following physical effects: disease-related illnesses, accident-related injuries, and illness from poisonous 
Table 3 Demographic characteristics of the elderly study participants $(n=290)$

\begin{tabular}{|c|c|c|}
\hline Characteristics & $n$ & $\%$ \\
\hline \multicolumn{3}{|l|}{ Age $($ years $)($ mean $=68.9)$} \\
\hline $60-69$ & 166 & 57.2 \\
\hline $70-79$ & 94 & 32.5 \\
\hline$\geq 80$ & 30 & 10.3 \\
\hline \multicolumn{3}{|l|}{ Gender } \\
\hline Male & 104 & 35.9 \\
\hline Female & 186 & 64.1 \\
\hline \multicolumn{3}{|l|}{ Marital status } \\
\hline Married & 178 & 61.4 \\
\hline Widowed/divorced/separated & 102 & 35.2 \\
\hline Single & 10 & 3.4 \\
\hline \multicolumn{3}{|l|}{ Educational background } \\
\hline No formal education & 13 & 4.5 \\
\hline Primary education & 239 & 82.4 \\
\hline Secondary education & 31 & 10.7 \\
\hline College/University & 7 & 2.4 \\
\hline \multicolumn{3}{|l|}{ Current employment } \\
\hline Unemployed & 201 & 69.3 \\
\hline Employed & 89 & 30.7 \\
\hline \multicolumn{3}{|c|}{ Personal Income (per month) $($ mean $=$ US $\$ 112.8)$} \\
\hline$<$ US $\$ 143(<5,000$ Baht $)$ & 199 & 68.6 \\
\hline US \$143-286 (5,000-10,000 Baht) & 81 & 27.9 \\
\hline$>$ US $\$ 286$ (>10,000 Baht) & 10 & 3.5 \\
\hline \multicolumn{3}{|l|}{ Sufficiency of income } \\
\hline Sufficient with savings & 46 & 15.9 \\
\hline Sufficient with no savings & 206 & 71.0 \\
\hline Insufficient & 38 & 13.1 \\
\hline \multicolumn{3}{|l|}{ Living arrangement } \\
\hline Living alone & 16 & 5.5 \\
\hline Living with spouse/child/relatives & 274 & 94.5 \\
\hline \multicolumn{3}{|l|}{ Perception of health } \\
\hline Good & 59 & 20.3 \\
\hline Fair & 194 & 66.9 \\
\hline Poor & 37 & 12.8 \\
\hline \multicolumn{3}{|l|}{ Personal health problems (chronic diseases) } \\
\hline No & 74 & 25.5 \\
\hline Yes & 216 & 74.5 \\
\hline \multicolumn{3}{|l|}{$\begin{array}{l}\text { Personal health compared to other elderly } \\
\text { persons in the same age group }\end{array}$} \\
\hline Better & 117 & 40.3 \\
\hline Same & 138 & 47.6 \\
\hline Worse & 35 & 12.1 \\
\hline \multicolumn{3}{|l|}{ Disability } \\
\hline No & 274 & 94.5 \\
\hline Yes & 16 & 5.5 \\
\hline
\end{tabular}

Table 4 Health effects experienced by the elderly study participants $(n=290)$

\begin{tabular}{lcc}
\hline \multicolumn{1}{c}{ Health effect items } & $n$ & $\%$ \\
\hline 1. Flood-related diseases & 102 & 35.2 \\
- Muscle ache, muscle pain & 95 & 32.8 \\
- Respiratory diseases (e.g., common cold, asthma, & & \\
pneumonia, coughing, etc.) & 82 & 28.3 \\
- Athlete's foot & 67 & 23.1 \\
- Skin rashes & 20 & 6.9 \\
- Gastrointestinal diseases (e.g., diarrhea, food & & \\
poisoning) & 7 & 2.4 \\
- Conjunctivitis & & \\
2. Accidents & 19 & 6.6 \\
- Slipping/falling & 6 & 2.1 \\
- Vehicle-related accidents & 3 & 1.0 \\
- Cuts/penetrating wounds & 3 & 1.0 \\
- Electric shock & & \\
3. Animal bites & 4 & 1.4 \\
- Snakes & 3 & 1.0 \\
- Centipedes & 1 & 0.3 \\
- Scorpions & & \\
4. Treatment & 222 & 76.6 \\
- No prescription given by the doctor & 222 & 76.6 \\
- Inconvenience traveling to a healthcare service & & \\
- center & 219 & 75.5 \\
\hline - Inability to keep the doctor's appointment & &
\end{tabular}

animals. The most prevalent health problems reported were muscle pain $(35.2 \%)$, respiratory infection $(32.8 \%)$, athlete's foot $(28.3 \%)$, and skin rash $(23.1 \%)$. Some participants suffered a fall $(6.6 \%)$. Also, they suffered a lack of access to the medication prescribed by doctors $(76.6 \%)$, inconvenience in traveling to healthcare service facilities $(76.6 \%)$, and inability to keep doctors' appointments (75.5\%), as shown in Table 4.

Concerning psychological health effects, the elderly participants might have had mental health problems (24.3\%). The psychological health problems encountered were insomnia, feeling of constant stress, attention deficit, discontentment, and depression.

\section{The elderly's experience of flood and adaptation}

Over the past 5 years, every elderly participant had encountered flood disasters at least once. As for the flood disaster of 2011, in particular, nearly every participant (98.6\%) reported the disaster to have been more severe than other disasters in the past. More than half of them (53.4\%) had incurred damages from flood disasters, but almost three-quarters (72.8\%) received assistance or 
support with various aspects, with more than half of them receiving monetary support and assistance, particularly for health care and treatment of illnesses.

As for the decisions to evacuate or not evacuate, most of the participants $(89.3 \%)$ decided not to move because they thought they could still live at home, because they were concerned about their properties; they thought the flooding would not last long, they were attached to their homes, they did not want to move to evacuation centers and have elderly persons/disabled persons to care for, etc. In contrast, the remaining $10.7 \%$ who decided to evacuate moved to stay with their children and relatives where there was no flood.

When considering adaptation of elderly persons to cope with floods, it could be seen that the elderly persons themselves, their family, and their community prepared consumer products and important documents in preparation. The findings revealed that almost all of the elderly persons and their families (94.1\%) prepared consumer goods such as drinking water, rice, and dried or preserved food. In addition, $66.2 \%$ prepared important documents in a plastic container, $62.8 \%$ prepared necessary medication, and $53.8 \%$ prepared emergency kits including matches, candles, etc. Furthermore, the community prepared for the flood disaster by having public announcements about evacuation plans, and the elderly persons and their families kept abreast with news and flood forecasts from television (77.6\%) and public announcement systems (37.9\%). Finally, in terms of adaptation of the residence in preparation for the floods, $79.0 \%$ moved their belongings up to a higher place, $39.0 \%$ prepared sand bags, and $37.2 \%$ prepared the space for moving their belongings, all of which involved collaborative efforts from the elderly persons, their families, and the community, as shown in Table 5.

\section{DISCUSSION}

Regarding health effects and adaptation of elderly persons who faced the major flood in 2011, it was found that the health effects could be divided into flood-related diseases and accidents. The flood-related diseases included respiratory infection, athlete's foot, and skin rashes. In contrast, accidents that took place included falls, snake bites, etc. These findings yielded support to previous findings on physical health problems of people who had experienced flood impact. For instance, a study of health impacts, perceptions, and adaptation of people who encountered forest flooding disasters and landslides in Uttaradit, Thailand (Pinyaphong, 2008) found that encountered health problems were symptoms of athlete's
Table 5 Adaptation tasks carried out by elderly study participants in preparation for future flood events

\begin{tabular}{|c|c|c|}
\hline & $n$ & $\%$ \\
\hline \multicolumn{3}{|l|}{$\begin{array}{l}\text { 1. Preparation of consumer goods and important } \\
\text { documents }\end{array}$} \\
\hline $\begin{array}{l}\text { - Storing consumer goods such as drinking water, } \\
\text { rice, preserved food, etc. }\end{array}$ & 273 & 94.1 \\
\hline - Keeping documents and valuables in a plastic bag & 192 & 66.2 \\
\hline - Preparing medication & 182 & 62.8 \\
\hline $\begin{array}{l}\text { - Preparing emergency kits that include matches, } \\
\text { candles, etc. }\end{array}$ & 156 & 53.8 \\
\hline - Preparing medication and first-aid kits & 127 & 43.8 \\
\hline - Preparing spare clothes & 75 & 25.9 \\
\hline - Preparing boats/rafts & 39 & 13.4 \\
\hline \multicolumn{3}{|l|}{$\begin{array}{l}\text { 2. Keeping up with the news and planning for } \\
\text { evacuation }\end{array}$} \\
\hline - Following flood forecasts on television & 225 & 77.6 \\
\hline $\begin{array}{l}\text { - Paying attention to community public } \\
\text { announcements }\end{array}$ & 110 & 37.9 \\
\hline $\begin{array}{l}\text { - Contacting children, relatives, or friends when } \\
\text { in need }\end{array}$ & 56 & 19.3 \\
\hline - Preparing contact information of related agencies & 40 & 13.8 \\
\hline \multicolumn{3}{|l|}{$\begin{array}{l}\text { 3. Modification of residence to reduce severity of } \\
\text { flood-related damage }\end{array}$} \\
\hline - Putting belongings up high to avoid damage & 229 & 79.0 \\
\hline - Building sandbag walls & 113 & 39.0 \\
\hline - Preparing space to move belongings to & 108 & 37.2 \\
\hline - Erecting concrete walls & 43 & 14.8 \\
\hline - Raising house level & 36 & 12.4 \\
\hline
\end{tabular}

foot or skin disease $(49.0 \%)$, and fevers and rashes (27.7\%). Similarly, a study of flooding impact in Nongkai, Thailand, revealed that many people were sick with diseases where water was a medium (64.2\%), with most of the patients having athlete's foot (85.7\%), followed by rash/itchy rash/hives, and conjunctivitis/ eye inflammation (32.8\%) (Sidet \& Inmuong, 2010). In contrast, accident-related effects encountered by most participants included slipping/falling, which was similar to that reported by Sidet \& Inmuong (2010), who found that the most common accident-related injuries caused by flood disasters were slipping/falling, poisonous animal bites, and cuts/piercing/stabbing with sharp objects hidden under the flood water. As such, it could be concluded that during floods, both flood-related diseases and accidents were inevitable. Therefore, a guideline should be devised to disseminate knowledge about floodrelated diseases, accident prevention, and first-aid care.

Another major health effect was caused by the inability of elderly persons to travel to their doctor's appointment 
to get their prescription. In general, elderly persons tend to have chronic conditions that require constant meeting with the doctors and medication intake. In this study, it was found that floods made it inconvenient or difficult for them to go to the hospital, so they did not get their prescribed medication and their health could be adversely affected. Likewise, Sidet \& Inmuong (2010) found that almost half of the study participants experienced inconvenience in traveling to healthcare service facilities (45.4\%). The above findings also concurred with a survey of families in flooded areas during July-December 2011, which indicated that $15.3 \%$ of the persons living in flooded areas had family members who used medical services. Of these, $1.2 \%$ were unable to receive services as usual. The inability to maintain stable medication intake during flood situations may be a contributing factor to worsened flood-related health outcomes (Alderman, Turner, \& Tong, 2013). In fact, when elderly persons are unable to continuously take their medication or keep their doctor's appointment, the prognosis of their illnesses may be worsened and they may not be able to control their diseases. Thus, the public health service system needs to prepare for the problems by, for example, prescribing more medication that would last $4-8$ weeks instead of the usual 2-4 weeks, and organizing a mobile medical service for home visits to elderly persons.

According to the study findings, elderly participants had mental health problems that included insomnia, a feeling of constant stress, attention deficit, discontentment, and depression. Such findings were consistent with previous studies on mental health impacts of flood disasters (Ahern, Kovats, Wilkinson, Few, \& Matthie, 2005; Chae et al., 2005; Tunstall, Tapsell, Green, Floyd, $\&$ George, 2006). The psychological health problems encountered were insomnia and a feeling of constant stress, which was found to be similar to the findings from the study by Pinyaphong (2008), who found that disaster victims were unable to sleep because they were thinking too much or had anxiety about flooding (33.8\%). Also, Sidet \& Inmuong (2010) reported that most people were anxious about damage to homes and indoor properties $(27.3 \%)$, followed by anxiety concerning inconveniences in daily life, which caused impacts on health such as insomnia (72.7\%) and stress (58.8\%). Moreover, in a study of risk factors influencing the existence of stress after flooding in Ang Thong, Thailand, disaster victims were found to have stress during the floods, and the risk factors influencing and correlating with the existence of stress were being aged of over 60 years and a low/ inadequate income (Wichitnak, Sintuprasit, Saralook, \& Padungyat, 2007). A similar finding on psychological health impacts from floods was also reported in a study undertaken in South Korea in 2002 (Chae et al., 2005), where flood victims had symptoms of illness such as insomnia and headaches. Therefore, it can be concluded that stress has a significant impact on psychological conditions, and the severity of the psychological health problems may depend on multiple factors such as loss of properties, loss of loved ones, feelings of helplessness, and absence of psychological counseling.

In terms of adaptation, every elderly participant had endured at least one previous flood disaster. In this study, most of the participants decided not to evacuate and had high adaptation skills for flood disaster preparation and mitigation. Similarly, previous studies found that most of the people and their families remained in the same area of flood disasters because of attachment to lifestyles and homes, ability to live in the area, concern for homes/ properties, and beliefs that the floods would not last long (Pinyaphong, 2008; National Statistical Office, 2012). In addition, a previous survey found that the level of evacuations depended on flood disaster experiences, with more people who had no experience evacuating $(21.1 \%)$ compared to those who had experience with evacuation (15.6\%) (National Statistical Office, 2012).

When considering the participants' preparations for floods, it could be seen that most of the participants prepared consumer goods, medication for chronic diseases, and emergency equipment and tools such as matches and candles. In terms of listening to news and cooperating with communities, the participants were found to have followed news and information broadcast on television, collected documents and valuables in plastic bags, showed interest in community public announcements, and cooperated with communities in digging drainage canals/ditches, etc. With regard to modifying home conditions, the participants were found to have moved objects to a higher position, put sandbag walls in place, prepared areas to move objects to, built cement walls, raised house levels, and prepared water pumps. Their efforts were meant to help prevent and reduce the severity of the disaster. According to the findings of Pinyaphong (2008), when it came to adaptation to reduce the severity of new disasters, most of the people were found to have modified behaviors in terms of cooperating with digging and modifying streams at shallow parts for the water to flow more easily, monitoring news from various media, and making preparations to handle potential disasters such as transporting items to safe places and storing food and drinks for survival. As reported in a survey of households in flooded areas between July and August 2011 (National 
Statistical Office, 2012), over half of the households in the flooded areas $(53.9 \%)$ prepared for flood situations by moving objects to high places, which could be easy and inexpensive to perform, putting sandbag walls in place, and storing food and necessities, etc.

With regard to preparedness and mitigation, the community initiated plans to decrease potential health effects. In fact, the community played a significant role in helping the elderly and their family members prepare and deal with flood impacts. In addition, community participation via being attentive to community broadcasts, taking part in drainage clearance activities, and discarding garbage in provided places could significantly reduce the health effects. In this study, only $53.4 \%$ of the elderly participants suffered damage to their houses from flood disasters. However, it is worth noting that government organizations need to work closely and effectively in collaboration with community leaders, health volunteers, and community members to protect vulnerable elderly from possible flood disaster impact.

\section{ACKNOWLEDGMENTS}

This research was undertaken as a part of the Disaster Nursing Education Project in collaboration with the Japanese Red Cross College of Nursing and the Thai Red Cross College of Nursing for disaster nursing teaching and learning development in Thailand. Much appreciation goes to The Japanese Red Cross College of Nursing, with funds made available by the Supported Program for the Strategic Research Foundation of Private Universities of the Ministry of Education, Culture, Sports, Science and Technology in Japan.

\section{AUTHOR CONTRIBUTIONS}

$\mathrm{SC}$ was responsible for the study conception and study design; SC and WI collected the data; SC performed the data analysis and drafted the manuscript; SC and WI made critical revisions to the paper for important intellectual content; and WI supervised the study.

\section{DISCLOSURE}

No conflicts of interest have been declared by the authors. None of the authors of this paper have any interest, financial or otherwise, which may have biased the planning, execution, analysis, or writing up of this research study.

\section{REFERENCES}

Ahern, M., Kovats, S., Wilkinson, P., Few, R., \& Matthie, F. (2005). Global health impacts of floods: epidemiologic evidence. Epidemiologic Review, 27, 36-46.

Alderman, K., Turner, L. R., \& Tong, S. (2013). Assessment of the health impacts of the 2011 summer floods in Brisbane. Disaster Medicine and Public Health Preparedness, 7 (4), 380-386.

Allen, K. B. (2010). Populations with vulnerabilities and special needs. In: R. Power \& E. Daily (Eds.), Disaster Nursing International, (pp. 289-304). New York: Cambridge University Press.

Centre for Research on the Epidemiology of Disaster (CRED) (2017). Disaster Data: A Balanced Perspective. [Cited 10 February 2015.] Available from URL: www.preventionweb. net

Chae, E.-H., Kim, T. W., Rhee, S.-J., \& Henderson, T. D. (2005). The impact of flooding on the mental health of affected people in South Korea. Community Mental Health Journal, 41 (6), 633-645.

Department of Mental Health. (2011). The General Health Questionnaire (GHQ-12) Thai version. [Cited 10 February 2012.] Available from URL: www.dmh.go.th/eBook (in Thai)

Department of Provincial Administration. (2010). Statisticed information service. [Cited 10 February 2015.] Available from URL: http://dopa.go.th/public_service (in Thai)

Fowler, J., Jarvis, P., \& Chevannes, M. (2002). Practical statistics for nursing and health care. New York: John Wiley \& Sons, Inc.

IBM Corporation. (2013). IBM SPSS statistics for windows, version 22.0. Armonk, NY: IBM Corporation.

National Disaster Prevention and Mitigation Committee. (2015). National disaster prevention and mitigation plan B.E.2555. Bangkok: Office of National Buddhism Press. (in Thai)

National Statistics Office. (2012). Household survey in flooded areas during July -December 2011. Bangkok: National Statistics Office. (in Thai)

Pinyaphong, J. (2008). Health impact perception and adaptation of people from flash floods and mudslide disaster in Uttaradit Province. Journal of Public Health, Special issue on $60^{\text {th }}$ Anniversary of Faculty of Public Health, 9-20. (in Thai)

Sidet, C., \& Inmuong, U. (2010). Impact of flooding on people's health in Wieng Kook sub-district, Muang district, Nongkhai province. Khon Khen University Journal of Public Health Research, 3 (3), 65-74. (in Thai)

Tunstall, S., Tapsell, S., Green, C., Floyd, P., \& George, C. (2006). The health effects of flooding: social research results from England and Wales. Journal of Water and Health, 4 (3), 365380 .

Wichitnak, S., Sintuprasit, S., Saralook, P., \& Padungyat, J. (2007). Risk factors causing persistence of stress after flood disaster stress in Augthong province. Journal of Health Systems Research, 1 (2), 182-187. (in Thai)

World Health Organization. (2017). Environmental health in emergencies: vulnerable group. [Cited 3 March 2017.] Available from URL: www.who.int/environmental_health_ emergencies/vulnerable_groups/en/ 